\title{
Survey of Mosquitoes in Students Hostels of Federal University of Lafia, Nasarawa State, Nigeria
}

\author{
Ombugadu $A^{1 *}$, Maikenti JI' ${ }^{1}$, Maro SA ${ }^{1}$, Vincent S0 ${ }^{1}$, Polycarp IA ${ }^{1}$, Pam VA ${ }^{1}$, Samuel MD ${ }^{1}$, Njila \\ $\mathrm{HL}^{2}$, Pam $\mathrm{DD}^{3}$, Deme $\mathrm{GG}^{4}$, Adejoh $\mathrm{VA}^{1}$, Echor $\mathrm{BO}^{2}$, Attah $\mathrm{AS}^{1}$, Igboanugo $\mathrm{SI}^{5}$, Yina $\mathrm{GI}^{3}$, Ahmed \\ $\mathrm{HO}^{1}$, Aimankhu OP${ }^{1}$, Luka J ${ }^{5}$, Ayuba SO ${ }^{1}$, Aliyu AA ${ }^{1}$, Anyim $\mathrm{JO}^{1}$, Micah EM ${ }^{1}$, Lapang $\mathrm{MP}^{3}$, Luka ${ }^{3}$, \\ Mamot $\mathrm{LP}^{3}$, Mafuyai $\mathrm{MJ}^{6}$, Nkup $\mathrm{CD}^{7}$, Angbalaga $\mathrm{GA}^{8}$, Uzoigwe $\mathrm{NR}^{1}$ and Mwansat GS ${ }^{3}$ \\ ${ }^{1}$ Department of Zoology, Faculty of Science, Federal University of Lafia, Nasarawa State, Nigeria.
}

${ }^{2}$ Department of Science Laboratory Technology, Faculty of Natural Sciences, University of Jos, Plateau State, Nigeria.

${ }^{3}$ Department of Zoology, Faculty of Natural Sciences, University of Jos, Plateau State, Nigeria.

${ }^{4}$ State Key Laboratory of Ecology and Conservation, Institute of Zoology, Chinese Academy of Science, Beijing 100101, PR China.

${ }^{5}$ Department of Zoology, Faculty of Natural Sciences, Nasarawa State University, Keffi, Nigeria.

${ }^{6}$ Department of Pest Management Technology, Forestry Research Institute of Nigeria, Federal College of Forestry, Jos, Plateau State, Nigeria.

${ }^{7}$ Department of Biology, College of Arts, Science and Technology, Kurgwi, Qua'an Pan LGA, Plateau State, Nigeria.

${ }^{8}$ Department of Microbiology, Faculty of Science, Federal University of Lafia, Nasarawa State, Nigeria.

*Corresponding author: Ombugadu A, Department of Zoology, Faculty of Science, Federal University of Lafia, Nasarawa State, Nigeria, E-mail: akwash24@gmail.com

\section{ARTICLE INFO}

Received: 蔧 June 27, 2020

Published: 蔧 July 07, 2020

Citation: Ombugadu A, Maikenti JI, Maro SA, Vincent SO, Polycarp IA, et al., Survey of Mosquitoes in Students Hostels of Federal University of Lafia, Nasarawa State, Nigeria. Biomed J Sci \& Tech Res 28(4)-2020. BJSTR. MS.ID.004691.

Keywords: Mosquitoes; Students Hostels; Altitude of building floors; Abdominal conditions; Transmission indices; Protection against mosquitoes bite

\section{ABSTRACT}

The presence of mosquitoes in an academic environment is a great threat to both staff and students well-being due to the possibility of the transmission of mosquitoborne diseases if bitten by an infected mosquito. Thus, this study surveyed mosquitoes in students hostels of Federal University of Lafia, Nasarawa State, Nigeria between August and October, 2019 using the Prokopack Aspirator for mosquitoes day catch from 0600 hours to 0900 hours. A total of 114 mosquitoes were collected in which the predominant species was Culex quinquefasciatus 65(57.0\%) followed by Anopheles gambiae 41(36.0\%) then Aedes aegypti and Mansonia uniformis with 3(2.6\%) each, while Anopheles squamosus and Anopheles coustani were the least with $1(0.9 \%)$ each. Hence, there was a high significant difference in abundance between the six mosquito species $(\mathrm{P}<0.001)$. The abundance of mosquitoes was more in male hostel $79(69.3 \%)$ than in the female hostel 35(30.7\%) which showed a significant difference ( $\mathrm{P}=0.03636)$. Mosquitoes abundance significantly varied $(\mathrm{P}<0.05)$ in relation to altitude of building floors in favor of ground floor hostels rooms. Most of the female mosquitoes were blood fed 72(69.2\%). Transmission indices revealed 2 mosquitoes/room and as well as 1 mosquito/student. $100.0 \%$ of the rooms don't use insecticide aerosols and thus mosquitoes were caught in all rooms while $75.30 \%$ of such rooms use treated bed nets but still yet $81.2 \%$ mosquitoes were caught. Mosquitoes abundance positively increased ( $\mathrm{r}=0.041)$ with increase in number of sleepers in rooms. This is the first study on mosquitoes populations in the Institution's students hostels which will serve as a baseline data for mosquitoes control in the University environment. Students should avoid human-vectors contact by use of insecticides and treated bed nets. 


\section{Introduction}

Mosquito are small slender insect dreaded by humans with fragile wing measuring about 4-6mm [1]. The female mosquito sucks the blood of their host which includes humans, horses and other vertebrates. Mosquitoes bite on host after sometime results to a red-ringed bump in the body of the host $[1,2]$. Mosquito are worldwide in distribution [3] and have well developed adaptation that enable them to thrive during breeding in various environment such as contaminated and clean little water bodies, buckets, tyres and hoof prints [4]. Anthropogenic activities such as road construction, mining, irrigation farming which are intended to improve the quality of life of people give rise to breeding sites that are of favorable condition for disease vectors to thrive [46]. Mosquitoes are mostly found around human dwelling and in school environment [7-9] and are responsible for the transmission of diseases such as malaria, yellow fever, filariasis, denque which causes morbidity, mortality and socio-economic loss [10].

WHO [11] estimate that, over 438,000 malaria deaths worldwide and most of these death occurred in the African Region (90\%) followed by the south-east Asia Region (7\%) and the Eastern Mediterranean Region (2\%). Nigeria bears the highest burden of malaria and lymphatic filariasis with an estimated 80 to 120 million people at risk [12]. A report by WHO [13] showed that of the $85 \%$ malaria most hit countries, Nigeria had the highest number of cases and deaths of $25 \%$ and $24 \%$ respectively. The students hostels of Federal University of Lafia was commissioned in 2019 for students habitation. Also, at present there is ongoing construction of roads and building of structures on the campus, and as well as presence of rice paddy which are all giving rise to potential mosquitoes breeding habitats in the school environment. Hence, the survey of mosquitoes in students hostels of Federal University of Lafia, Nasarawa State, Nigeria was embarked upon so as to serve as the first entomological baseline data which will guide the decision of the Management in relation to vectors control for the well-being of students against mosquito-borne diseases.

\section{Materials and Methods}

\section{Study Area}

The study was conducted in students hostels of Federal University of Lafia (FULafia) located on latitude: $8^{\circ} 29^{\prime} 38^{\prime \prime} \mathrm{N}$ and longitude: $8^{\circ} 30^{\prime} 5^{\prime \prime} \mathrm{E}$ (Figure 1). The campus is situated in the Capital of Nasarawa State. The predominant occupation of the people of Lafia people is farming. The temperature and relative humidity of Lafia is high. The wet season lasts for seven months which is between April and October, while the dry season is between November and March [14].

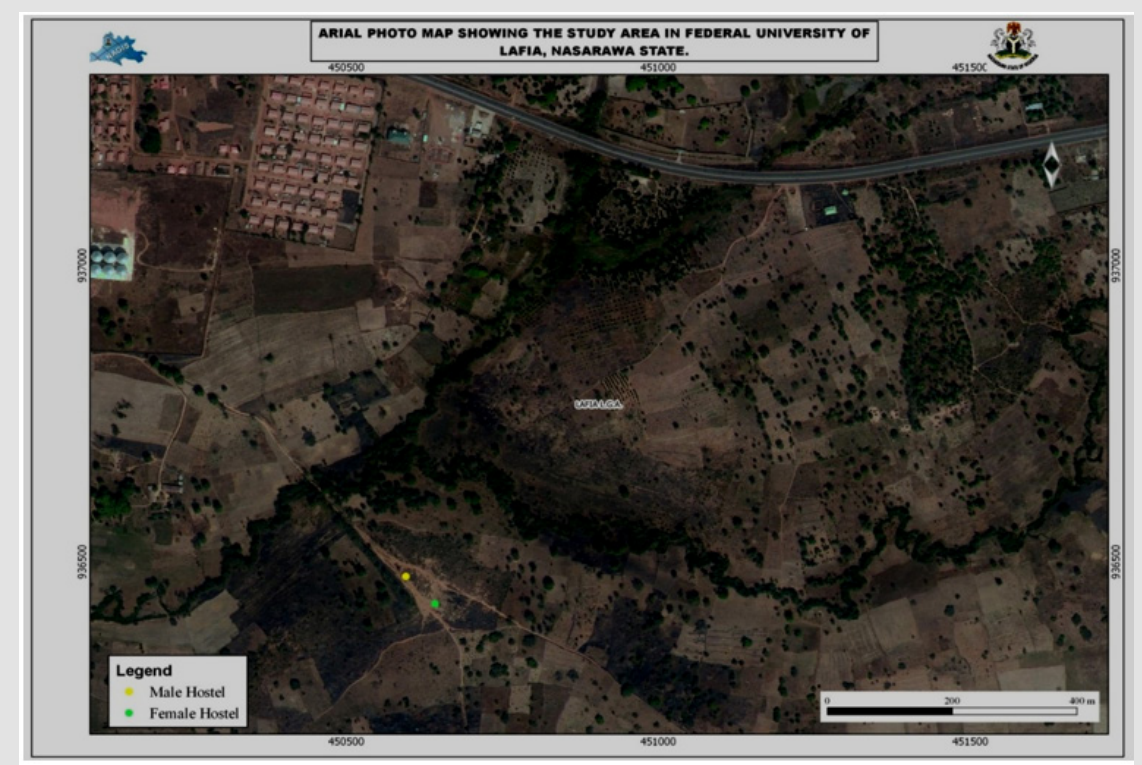

Figure 1: Aerial Photo Map of Federal University of Lafia, Nasarawa State showing the location of students hostels.

\section{Mosquitoes Collection}

Mosquitoes were collected indoors in the male and female students hostels between August and October, 2019 during the late raining season period. A total of 64 rooms were sampled in which 32 rooms were selected from male and female students hostels respectively, and the systematic sampling technique was used to select 8 rooms in each floor of the hostels in which an interval of two rooms was considered between the selected rooms. Rooms were selected a day prior to collection and occupants of the rooms were informed to keep doors and windows closed until it was sampled. Each room was visited twice within the study period. Trapping of adult mosquitoes was done using battery powered Prokopack Aspirator during the morning period (day time) between 0600 hours and 0900 hours. Mosquitoes trapped in the collection cup attached to the Prokopack Aspirator were knocked down using cotton wool soaked in chloroform. Thereafter, samples were transferred into a well labeled petri-dish for each room and transported to the laboratory for sorting and morphological identification. 


\section{Morphological Identification}

Mosquitoes were sorted out and morphologically identified based on their visible features with the aid of a dissecting microscope and identification keys by Service [1], Carpenter and LaCasse [15], Gillies and Coetzee [16], Darsie and Ward [17] and Kent [18]. Identified mosquitoes were preserved in eppendorf tube containing silica gel for further processing.

\section{Statistical Analysis}

Data obtained were analyzed using $\mathrm{R}$ Console software (Version 3.2.2). Pearson's Chi-square test was used to compare abundance between mosquito groups, species, and sex. Welch two sample t-test was used to compare mean abundance of mosquitoes in relation to male and female hostels, and as well as between sleeping and bathing rooms. One-way analysis of variance (ANOVA) was used to compare mean abundance of mosquitoes in relation to building floors altitude. Pearson's product-moment correlation was used to determine the association between mosquitoes abundance and number of sleepers in rooms. Level of significance was set at $\mathrm{P}<0.05$.

\section{Entomological Transmission Indices}

\section{A. Indoor Resting Density of Mosquitoes}

The indoor resting density (IRD) of female mosquitoes per structure per night was calculated using the formula by Williams and Pinto [4]:

$$
I R D=\frac{\text { Total number of vectors collected }}{\text { Total number of rooms sprayed }}
$$

\section{B. Man Biting Rate}

Man biting rate (MBR) is expressed as the number of bites a person receives from a specific vector species per night. This parameter can indirectly be estimated from mosquito day catches using the formula by Williams and Pinto [4] below:

$M B R=\frac{\text { Number of mosquitoes collected }}{\text { Number of people that slept in the rooms the previous night }}$

\section{Diversity Index}

Shannon-Wiener diversity index according to Begon et al. [19] and Lamead [20] was used to determine the diversity level of mosquitoes in the area.

$$
H^{\prime}=-\sum_{i=1}^{S}(P i)(\ln P i)
$$

Where:

$H^{\prime}$ is the diversity index

$P i$ is the proportion of individual species

$S$ is the total number of species in the habitat and $i$ is the proportion of $S$ species

Diversity index is on a scale of 0 to 5 where an index value between 0-2.4 shows a low diversity while 2.5-5 indicates high diversity.

\section{Results}

\section{Composition of Mosquito Species in Students Hostels of Federal University of Lafia, Nasarawa State}

A total of 114 indoor resting adult mosquitoes in students hostels of Federal University of Lafia were caught which belong to anopheline and culicine groups that spread across six species namely, Anopheles gambiae, Anopheles squamosous, Anopheles coustani, Culex quinquefasciatus, Aedes aegypti and Mansonia uniformis (Table 1). The culicine group had a higher number of individuals $71(62.3 \%)$ than the anophelines $43(37.7 \%)$. Thus, abundance of mosquitoes between the two groups showed a high significant difference $\left(\chi^{2}=6.8772, \mathrm{df}=1\right.$, $\mathrm{P}=0.0087)$. The predominant of the mosquito species caught was Culex quinquefasciatus 65(57.0\%) followed by Anopheles gambiae 41(36.0\%) then Aedes aegypti and Mansonia uniformis with 3(2.6\%) each while Anopheles squamosus and Anopheles coustani were the least with $1(0.9 \%)$ each (Table 1$)$. Therefore, there was a very high significant difference $\left(\chi^{2}=197.89, \mathrm{df}=5\right.$, $\mathrm{P}<0.001$ ) in abundance between the six mosquito species recorded. Female mosquitoes were more 104(91.2\%) than males $10(8.8 \%)$ (Table 1$)$. Hence, there was a high significant difference $\left(\chi^{2}=77.509\right.$, $\mathrm{df}=1, \mathrm{P}<0.001$ ) in abundance across mosquitoes sex.

Table 1: Checklist of mosquito species in male and female students hostels of Federal University of Lafia, Nasarawa State between August and October, 2019.

\begin{tabular}{|c|c|c|c|}
\hline \multirow{2}{*}{ Species } & \multicolumn{2}{|c|}{ Hostels } & \multirow{2}{*}{ Total (\%) } \\
\cline { 2 - 3 } & Male & Female & \\
\hline Aedes aegypti & 2 & 1 & $3(2.6)$ \\
\hline Anopheles coustani & 1 & 0 & $1(0.9)$ \\
\hline Anopheles gambiae & 27 & 14 & $41(36.0)$ \\
\hline $\begin{array}{c}\text { Anopheles } \\
\text { squamosus }\end{array}$ & 1 & 0 & $1(0.9)$ \\
\hline $\begin{array}{c}\text { Culex } \\
\text { quinquefasciatus }\end{array}$ & 46 & 19 & $65(57.0)$ \\
\hline Mansonia uniformis & 2 & 1 & $3(2.6)$ \\
\hline Total (\%) & $79(69.3)$ & $35(30.7)$ & 114 \\
\hline
\end{tabular}

Comparison of Mosquitoes Abundance in Relation to Hostels; Altitude of Building Floors; and Sleeping/ Bathing Rooms

Hostels: The abundance of mosquitoes was more in male hostel $79(69.3 \%)$ than in female hostel 35(30.7\%). Therefore, the mean abundance of mosquitoes between female and male hostels showed a significant difference $(t=-2.1172, d f=116.96, P=0.03636$, Figure 2). 


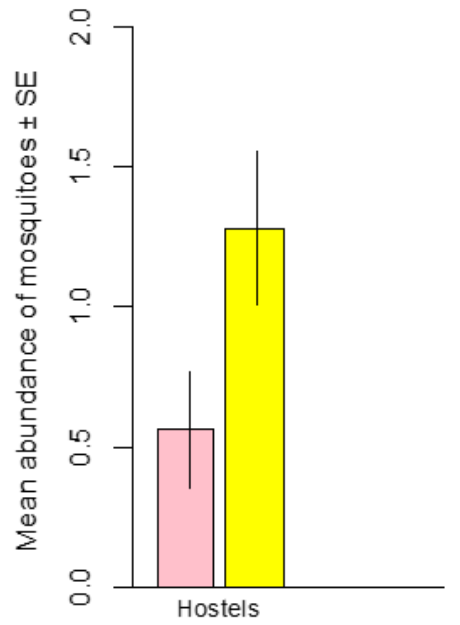

Female Hostel

Male Hostel

Figure 2: Mean abundance of mosquitoes in relation to female and male students hostels of Federal University of Lafia.

Altitude of Building Floors: Ground floor had the highest mosquitoes population $47(41.2 \%)$ followed by first floor $40(35.1 \%)$ then third floor $16(14.0 \%)$ while second floor was the least. Thus, building floors. there was significant difference $\left(\mathrm{F}_{124}=2.678\right.$, Adjusted $\mathrm{R}^{2}=0.03813$, $\mathrm{P}=0.04998$, Figure 3 ) in mosquitoes abundance in relation to

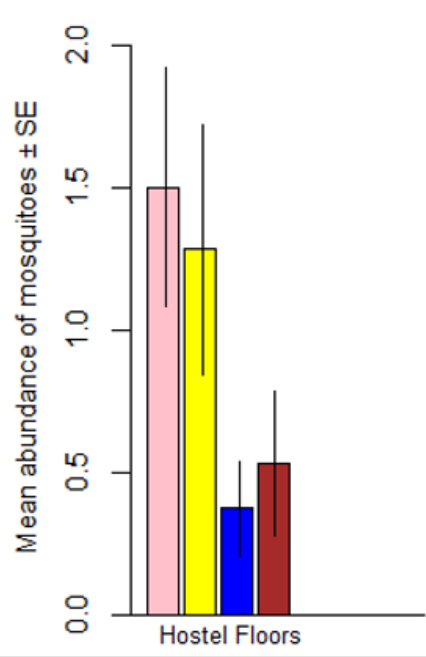

Figure 3: Mean abundance of mosquitoes in relation to hostels altitude of building floors.

Sleeping versus Bathing rooms: The number of mosquitoes was higher in bathrooms 68(59.6\%) than sleeping rooms 46(40.4\%). Hence, mosquitoes abundance between sleeping and bathing rooms showed a high significant difference $(\mathrm{t}=-3.0476$, $\mathrm{df}=33.87, \mathrm{P}=0.004451$, Figure 4). 


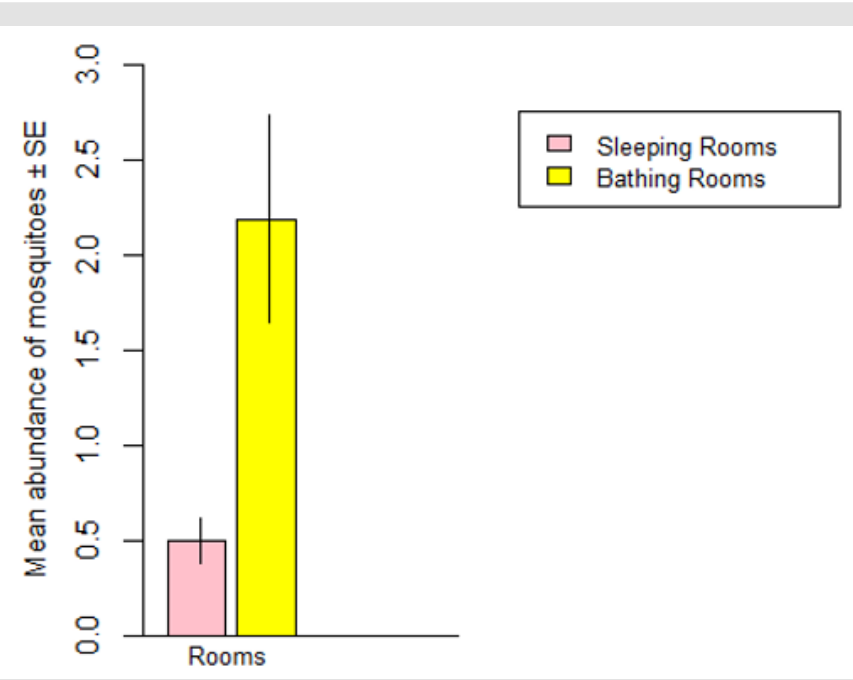

Figure 4: Mean abundance of mosquitoes in relation to sleeping and bathing rooms.

\section{Abdominal Conditions of Female Mosquitoes}

Most of the female mosquitoes collected were blood fed $72(69.2 \%)$ followed by those gravid $20(19.2 \%)$, then unfed
$9(8.7 \%)$ while the least was half gravid individuals $3(2.9 \%)$ (Table 2). Hence, abundance of female mosquitoes in relation to their abdominal conditions showed a very high significant difference $\left(\chi^{2}=114.23, \mathrm{df}=3, \mathrm{P}<0.001\right)$.

Table 2: Abdominal conditions of female mosquitoes caught in students hostels of Federal University of Lafia, Nasarawa State.

\begin{tabular}{|c|c|c|c|c|c|c|}
\hline \multirow{2}{*}{$\begin{array}{c}\text { Abdominal } \\
\text { Conditions }\end{array}$} & \multicolumn{5}{|c|}{ Mosquito species } \\
\cline { 2 - 6 } & Aedes aegypti & $\begin{array}{c}\text { Anopheles } \\
\text { coustani }\end{array}$ & $\begin{array}{c}\text { Anopheles } \\
\text { gambiae }\end{array}$ & $\begin{array}{c}\text { Anopheles } \\
\text { squamosus }\end{array}$ & $\begin{array}{c}\text { Culex } \\
\text { quinquefasciatus }\end{array}$ & $\begin{array}{c}\text { Mansonia } \\
\text { uniformis }\end{array}$ \\
\hline Unfed & 0 & 0 & 3 & 0 & 5 \\
\hline Fed & 3 & 1 & 33 & 1 & 33 \\
\hline Half Gravid & 0 & 0 & 0 & 0 & 2 \\
\hline Gravid & 0 & 0 & 2 & 0 & 1 \\
\hline Total (\%) & $3(2.9)$ & $1(1.0)$ & $38(36.5)$ & $1(1.0)$ & $2.9)$ & $20(19.2)$ \\
\hline
\end{tabular}

\section{Entomological Transmission Indices of Female Mosquitoes in Students Hostels}

Indoor resting density (IRD): an overall approximate IRD of 2 female mosquitoes per hostel room was recorded (Table 3).
An. gambiae and CX. quinquefasciatus have an approximate IRD of 1 mosquito per room whereas other mosquito species had an IRD that was less than 0.5 mosquitos per room as shown in Table 3.

Man biting rate (MBR): the pooled result from Table 3 showed that the MBR is one mosquito per student.

Table 3: Entomological transmission indices of female mosquitoes in students hostels.

\begin{tabular}{|c|c|c|c|}
\hline Species & No. of female mosquitoes & IRD/room (n=64 rooms) & MBR/person ( $\mathrm{n}=204$ persons) \\
\hline Aedes aegypti & 3 & 0.046875 & 0.015 \\
\hline Anopheles coustani & 1 & 0.015625 & 0.005 \\
\hline Anopheles gambiae & 38 & 0.59375 & 0.186 \\
\hline Anopheles squamosus & 1 & 0.015625 & 0.005 \\
\hline Culex quinquefasciatus & 58 & 0.90625 & 0.284 \\
\hline Mansonia uniformis & 3 & 0.046875 & 0.015 \\
\hline Total & 104 & 1.625 & 0.51 \\
\hline
\end{tabular}

The Association between Students Measures of Protec-

bite thus, mosquitoes were present in all rooms sampled (100.00\%) tion against Human-Vectors Contact and Mosquitoes Abundance

with at least 2 mosquitoes in each hostel room. Of the 36(75.30\%) rooms that hung insecticide treated bed nets (ITNs) a high number

Figure 5 showed that none of the student use aerosol insecticide in their hostels rooms as a means of protection against mosquitoes of mosquitoes were caught $37(81.20 \%)$ while those rooms that don't use ITNs $12(24.70 \%)$ had a low catch $9(18.80 \%)$. 


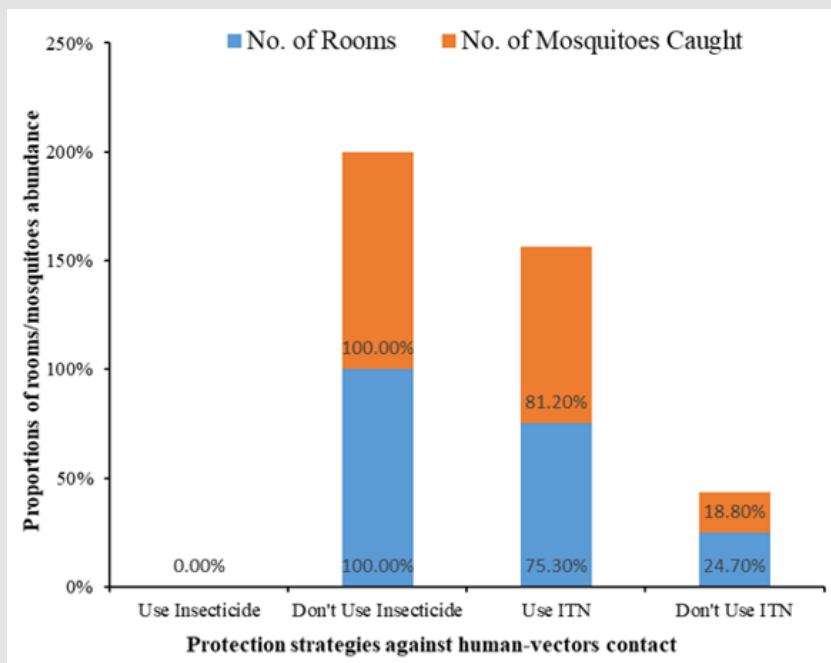

Figure 5: The association between protection strategies against human-vectors contact and mosquitoes abundance.

The Relationship between Number of People that Slept in Rooms and Mosquitoes Abundance

There was a weak positive relationship between mosquitoes abundance and the number of people that slept in rooms the previous night $(\mathrm{t}=0.39789, \mathrm{df}=94, \mathrm{P}=0.6916, \mathrm{r}=0.041$, Figure 6). The number of students in hostels rooms influenced mosquitoes abundance by $0.2 \%$ (coefficient of determination, $\mathrm{r}^{2}=0.002$ ).

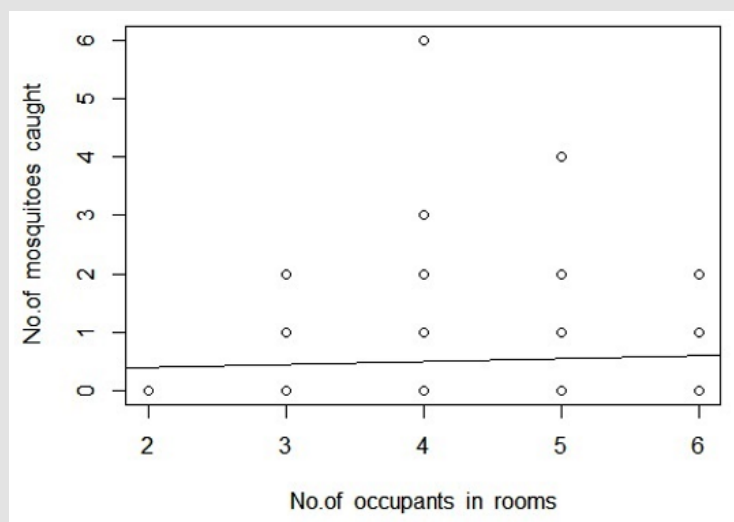

Figure 6: The association between numbers of people that slept in rooms the previous night and mosquitoes abundance.

\section{Mosquito Species Diversity Level in the Students Hostels}

Shannon-Wiener diversity index $\left(\mathrm{H}^{\prime}\right)$ obtained showed that mosquito species diversity was relatively low $\left(\mathrm{H}^{\prime} \approx 1.0\right)$ as shown in Table 4 .

Table 4: Mosquitoes diversity in students hostels using Shannon-Weiner diversity index.

\begin{tabular}{|c|c|c|c|c|}
\hline Species & Total & Pi & $\ln (\mathbf{P i})$ & Pi[ln(Pi)] \\
\hline Aedes aegypti & 3 & 0.026316 & -3.638 & -0.09573 \\
\hline Anopheles coustani & 1 & 0.008772 & -4.736 & -0.04155 \\
\hline Anopheles gambiae & 41 & 0.359649 & -1.023 & -0.36779 \\
\hline Anopheles squamosus & 1 & 0.008772 & -4.736 & -0.04155 \\
\hline Culex quinquefasciatus & 65 & 0.570175 & -0.562 & -0.32033 \\
\hline Mansonia uniformis & 3 & 0.026316 & -3.638 & -0.09573 \\
\hline Total & 114 & & & -0.9627 \\
\hline
\end{tabular}

$\mathrm{H}^{\prime}=-(-0.96)$

$\mathrm{H}^{\prime}=+0.96$

$\therefore \mathrm{H}^{\prime} \approx 1.0$ 


\section{Discussion}

Mosquitoes survey using the Prokopack Aspirator was efficient and effective based on species composition and abundance of biting and indoor resting mosquitoes caught in the students hostels in the Permanent Site of FULafia which is undergoing rapid development. The presence of mosquitoes in the students hostels will possibly expose the students to high risk of human-vectors contact that will result in transmission of mosquito-borne diseases which will negatively affect students performance due to loss of both lectures hours and scarce resources meant for upkeep to be used for purchase of drugs. This is in line with previous studies by Amusan et al. [21], Okwa et al. [22] and Adeoye et al. [23] who collected mosquitoes from students hostels of University of Agriculture, Abeokuta, Lagos State University (LASU), and University of Lagos respectively. Similarly, Madara [24] in a study on adult mosquitoes in University of Abuja main campus in FCT - Abuja, Nigeria recorded high number of mosquitoes belonging to three genera. Accordingly, Mistica et al. [9] documented the presence of mosquito species in public schools of Metro Manila in the Philippines. Furthermore, Ombugadu et al. [25] reported diverse and abundant mosquitoes in students private accommodation around the take-off site of FULafia in Mararraba-Akunza area.

Culex quinquefasciatus was the most dominant species collected possibly due to the short proximity between students hostels and houses in Lafia metropolis where a lot of polluted breeding sites are available thereby making it very easy for $C x$. quinquefasciatus to successfully breed and fly to the university environment. This is in accordance with Adeoye et al. [23] who showed that Culex quinquefasciatus was the most abundant mosquito species in students hostels of University of Lagos and its environment. Also, Mistica, et al. [9] recorded only culicine mosquitoes in public school environment. Likewise, Okwa and Sulaimon [26] noted more Culex than Anopheles in Ojo area of Lagos. On the contrary, studies by Onyido et al. [7], Madara et al. [24] and Ombugadu et al. [25] showed Anopheles gambiae proportion to be the predominant over other mosquito species in schools and its environs. Also, Okwa et al. [22,27,28] obtained more Anopheles than Culex mosquitoes in Badagry, six areas in Lagos and LASU students hostels respectively. Furthermore, Amusan et al. [21] showed that Aedes mosquito was the most abundant in students hostels of University of Agriculture, Abeokuta.

The presence of Anopheles gambiae as the second most dominant species in this study possibly suggests that the ongoing anthropogenic activities in the Permanent Site of the University have given rise to more temporary breeding sites (such as tyre tracks, hoof prints and rice paddy) for An. gambiae to successfully breed. This is in accordance with Williams and Pinto [4], Patricia et al. [10], Youdeowei and Service [29] and Adeleke et al. [30] who showed that transient habitats accounted for breeding success of Anopheles mosquitoes. Also, Adeoye et al. [23] reported An. gambiae as the second most abundant mosquito in a study on endophilic mosquitoes in students hostels of University of Lagos and its environment.

The high number of indoor resting female mosquitoes over males may be due to the need for blood meal in order to provide nutrient for the development of their fertilized eggs. Thus, this is of public health concern since it is only the female mosquito that bites and sucks blood during which mosquito-borne diseases may likely be transmitted into students as they feed. This agrees with the studies by Onyido et al. [7], Okwa et al. [22] and Madara et al. [24] who collected more female mosquitoes as compared to male mosquitoes in both male and female hostels. Consequently Okwa and Sulaimon [26], Okwa et al. [27,28], Lindsay and Birley [31] and Oyewole et al. [32] confirmed more female mosquitoes than males in their studies.

The observed variation in mosquitoes abundance in favor of male hostels may probably be due to the high amount of volatile compounds exuded by male students that attracts mosquitoes. This concurs with Bundy [33] who showed that male and female sex differ physiologically and biologically, thus resulting in variations in attractiveness to vectors. Also, mosquitoes are not attracted to females due to the fact that they have better immunity to malaria and other diseases which have been attributed to genetic or hormonal factors [34]. On the other hand, more female mosquitoes were collected from female students hostels than in male hostels of the Lagos State University in south-western, Nigeria [22].

The difference in mosquitoes abundance in relation to altitude of hostels floors possibly suggests that mosquitoes prefer the ground floor level due to presence of high number of students at dusk in the area which directly translates to high amount of volatile compounds being exuded on the ground flat. However, Onyido et al. [7] got most of their catches on the first floor rooms of the students hostels building of Nnamdi Azikiwe University Awka, Anambra State and South-eastern Nigeria.

The high number of mosquitoes in bathing rooms could be due to more favorable microclimatic conditions, dampness, easy access to exposed host body when cleaning up, and wet hanged clothes. This is in agreement with Entertainment Times [35] who pointed out bathrooms and toilets as one of the immense contributor to mosquitoes breeding success in and around house environment in India.

The variation across female mosquitoes abdominal (physiological) conditions clearly shows that the fed females are anthropophilic. This finding is in conformity with the works of Okwa et al. [22], Adeleke et al. [30], and Ebenezer et al. [36] in LASU, some parts of Abeokuta and Bayelsa States respectively. Also, most of the moquitoes caught by Amusan et al. [21] in students hostels of University of Agriculture, Abeokuta were blood fed individuals. 
This is not in agreement with the finding by Adeoye et al. [23] who recorded no difference in the physiological status of the endophilic mosquitoes caught in students hostels of University of Lagos and its environment.

The pooled indoor resting density of 2 mosquitoes per room in this study suggests a high likelihood of human-vector contact since occupants in each room is a maximum of 4 persons. Of the 2 mosquitoes per room, Anopheles gambiae and $C x$. quinquefasciatus were 1 each. This is in line with the finding of Onyido et al. [7] who reported a room density of 8 mosquitoes per room.

An overall man biting rate of 1 mosquito per student per night was observed which connotes a definite human-vector contact likely to occur. This is in agreement with the finding of Ombugadu et al. [25] who recorded a biting rate of 5 mosquitoes per man per hour.

The none usage of insecticidal aerosols by students in hostels rooms accounted for the presence of mosquitoes in all the rooms surveyed (100\%), although, some of the students use insecticide treated bed nets but still yet had more mosquitoes but wouldn't be bitten for the sake of sleeping under the treated bed net. Equally, Msugh-Ter et al. [8] found out that most undergraduate students of Federal University of Agriculture Makurdi protect themselves against mosquito bites by use of window and door nets.

This study shows that the higher the number of students that slept in hostels rooms the previous night the more the number of mosquitoes that were attracted indoors seeking for human host. This stands with Lwetoijera et al. [37] who showed that the density of mosquito increased as the number of people increased the more inside houses in rural Southern Tanzania.

The coefficient of determination $\left(0.2 \%, \mathrm{r}^{2}=0.002\right)$ recorded in this study implies that apart from the number of students being an attractive factor on the number of mosquitoes indoors visitors other microclimatic conditions such temperature and relative humidity as well played a much more vital role in influencing mosquitoes abundance in the hostels. Likewise, Ombugadu et al. [25] showed that temperature and relative humidity influences mosquitoes abundance at both indoor and outdoor points.

The low mosquitoes diversity index value recorded in this study signifies low species diversity in spite of the species richness observed. Möhlmann et al. [38] equally obtained a low diversity index value from mosquitoes collected in three European countries at different latitudes.

\section{Conclusion}

This study clearly showed that mosquitoes are present in FULafia's students hostels. The number of mosquitoes specimens collected during the study period was relatively low due to high amount of rainfall which flooded breeding sites in the area. The Culex quinquefasciatus population was the most dominant. Male hostel rooms had higher mosquito population. Most of the mosquitoes were collected in the ground floor hostels rooms. More mosquitoes were caught in bathing than sleeping rooms. The engorged females were the highest over the other abdominal conditions. The transmission indices revealed a relatively average indoor resting density and a definite human-vector contact. The lack of usage of insecticide aerosols by students in all the hostels rooms will make mosquitoes to fly into all the rooms unhindered despite the hung treated bed nets in most hostels rooms. Abundance of mosquitoes favorably increased with increase in number of sleepers in the rooms. Mosquitoes diversity level was on the low scale. The mosquitoes collected are of public health concern because they are known for the transmission of one form of disease or the other. Hence, students should avoid human-vectors contact by all means through the use of insecticides, treated bed nets and repellants. Mosquito-net screens should be placed on the doors and windows of both the hostels sleeping and bathing rooms since the students may not have enough funds to purchase insecticide aerosols at all times. Also, all the hostels rooms occupants should be provided with treated bed nets.

\section{Acknowledgement}

We are most grateful to the University authority for the permission to conduct the research. Also, we wish to thank the students of Fulafia that allowed mosquitoes collection in their rooms.

\section{References}

1. Service MW (2004) Medical Entomology for Students. $3^{\text {rd }}$ (Edn.) Cambridge University Press pp. 285.

2. Standfast HA (2002) A Guide to Medical Entomology. Macmillan Press Ltd., Ibadan.

3. WHO (1982) Manual on vectors control management for mosquitoes control with special emphasis on malaria Vectors. WHO off set publication 66(1): 1-283.

4. Williams J, Pinto J (2012) Training manual on Malaria Entomology for Entomology and Control Technicians (Basic Level). RTI International p. 78.

5. Sharma VP, Uppreathy HC (1982) Preliminary studies on irrigation malaria. Indian Journal of Malariology 19: 139-142.

6. Lapang PM, Ombugadu A, Ishaya M, Mafuyai MJ, Njila HL, et al. (2019) Abundance and Diversity of Mosquito Species Larvae in Shendam LGA Plateau State, North-Central Nigeria: A Panacea for Vector Control. Journal of Zoological Research 3(3): 25-33.

7. Onyido AE, Ndeezia PL, Obiukwu MO, Amadi ES (2008) Ecology of Man Biting Mosquitoes in the Development Site of Nnamdi Azikiwe University Awka, Anambra State, Southeastern Nigeria. The Internet Journal of Health 9(2): 1-7.

8. Msugh-Ter MM, Mngurumun AL, Emmanuel OI (2017) Personal Protective Practices Against Mosquito Bites by Undergraduate Students of Federal University of Agriculture Makurdi, North Central Nigeria. American Journal of Entomology 1(2): 27-30.

9. Mistica MS, Ocampo VR, De Las Llagas LA, Bertuso AG, Alzona FD, et al. (2019) A Survey of Mosquito Species in Public Schools of Metro Manila Philippines Using Ovitraps as Surveillance Tool. Acta Medica Philippina 53(4): 310-314.

10. Patricia NO, Popoola KOK, Olayemi MA, Kolade TI, Ademowo GO (2014) Species Composition and Temporal Distribution of Mosquito 
Populations in Ibadan, Southwest Nigeria. Journal of Entomology and Zoology Studies 2(4): 164-169.

11. WHO (2015) Fact Sheet: World Malaria Report 2015. Global Technical Strategy for Malaria pp. 2016-2030.

12. Hotez PJ, Asojo OA, Adesina AM (2012) Nigeria: Ground Zero for high prevalence of neglected tropical diseases. PLOS Neglected Tropical Diseases 6: e1600.

13. WHO (2019) World Malaria Report pp. 232.

14. Agidi VA, Hassan SM, Baleri TG (2017) Inter-Annual Rainfall Variability on Yam Yield in Lafia, Nasarawa State, Nigeria. PAT 13(2): 169-179.

15. Carpenter SJ, LaCasse WJ (1955) Mosquitoes of North America (North of Mexico).

16. Gillies MT, Coetzee M (1987) A supplement to the Anophelinae of Africa South of the Sahara (Afro tropical Region). Johannesburg: The South African Institute of Medical Research pp. 143.

17. Darsie RF, Ward RA (2004) Identification and geographical distribution of the mosquitoes of North America, north of Mexico. Mosquito Systematics Supplement 1: 1-313.

18. Kent RJ (2006) The mosquitoes of Macha, Zambia. PhD thesis in Johns Hopkins Malaria Research Institute, Department of Molecular Microbiology and immunology Johns Hopkins Blomberg School of public health Balti more M.D. USA, pp. 33.

19. Begon M, Harper JL, Townsend CR (2003) Ecology of individuals, California Press, Berkeley, pp. 360

20. Lamead GA (2011) Species diversity and abundance of Wild birds in Dagona Waterfall sanctuary Borno State, Nigeria. African Journal of Environmental Science and Technology 5(10): 855-866.

21. Amusan AAS, Mafiana CF, Idowu AB, Oke OA (2003) A survey of adult mosquitoes in the hostels of the University of Agriculture, Abeokuta, Ogun state Nigeria. Nigerian Journal of Parasitology 24(1): 167-172.

22. Okwa 00, Bello BA, Olundegun SA (2011) Human host preference of Anopheles mosquitoes collected from students hostels in a Nigerian university. South Asian Journal of Experimental Biology 1(3): 141-146.

23. Adeoye GO, Edeh IC, Olayiwola OA, Ayodele ET, Adeleke MA (2012) The abundance and composition of endophilic mosquito in the University of Lagos and its Environment. Nigeria Journal of Parasitology 33(1): 21-25.

24. Madara AA, Abdulraheem NO, Elkanah SO (2013) Relative Abundance of Adult Mosquitoes in University of Abuja Main Campus, Abuja FCT, Nigeria. Nigerian Journal of Parasitology 34(2): 79-84.

25. Ombugadu A, Ekawu RA, Pam VA, Odey SA, Igboanugo SI, et al. (2020) Feeding Behaviour of Mosquito Species in Mararraba-Akunza, Lafia
Local Government Area, Nasarawa State, Nigeria. Biomedical Journal of Scientific \& Technical Research 25(1): 18742-18752.

26. Okwa 00, Sulaimon R (2004) Dynamics of the transmission of Malaria in Ojo Local Government Area of Lagos Nigeria. Journal of Research and Review in Science 3: 1-6.

27. Okwa 00, Carter V, Hurd H (2006) Abundances, host preferences and infectivity rates of malaria vectors in Badagry Local Government Area of Lagos, Nigeria. Nigerian Journal of Parasitology 27(1): 41-48.

28. Okwa 00, Rasheed A, Adeyemi A, Omoyeni M, Oni L, et al. (2007) Anopheles species abundance, composition and vectoral competence in six areas of Lagos, Nigeria. Journal of Cell and Animal Biology 1(2): 1523.

29. Youdeowei A, Service MW (1986) Relationships between development programmes and health: In Pest and Vector Management in the tropics. ELBS edition pp 399.

30. Adeleke MA, Mafiana CF and Idowu OA (2010) Population Dynamics of indoor sampled mosquitoes and their implication in disease transmission in Abeokuta, south-western Nigeria. Journal of Vector Borne Disease 47(1): 33-38.

31. Lindsay SW, Birley MH (1996) Climate change and malaria transmission. Annals of Tropical Medicine and Parasitology 90: 573-578.

32. Oyewole IO, Awolola TS, Ibidapo CA, Okwa 00, Obansa JA (2007) Behavior and population dynamics of the major anopheline vectors in a malaria endemic area in Southern Nigeria. Journal of Vector Borne Diseases 44(1): 56-64.

33. Bundy DAP (1988) Gender dependent pattern of infection and disease. Parasitology Today 4(7): 186-189.

34. Brabin L, Brabin BJ (2005) HIV, Malaria and beyond: reducing the disease burden of adolescents. Malaria Journal 4: 2-18.

35. Entertainment Times (2017) 4 Places in and around your home where mosquitoes breed.

36. Ebenezer A, Ben HIB, Enaregha EB (2013) Atial distribution and indoorresting density of mosquito species in the lowland rainforest of Bayelsa State, Nigeria. International Journal of Tropical Medicine 8(4): 87-91.

37. Lwetoijera DW, Kiware SS, Mageni ZD, Dongus S, Harris C, et al. (2013) A need for better housing to further reduce indoor malaria transmission in areas with high bed net coverage. Parasites Vectors 6: 57.

38. Möhlmann TWR, Wennergren U, Tälle M, Favia G, Damiani C, et al (2017) Community analysis of the abundance and diversity of mosquito species (Diptera: Culicidae) in three European countries at different latitudes. Parasites Vectors 10(1): 510.
ISSN: 2574-1241

DOI: $10.26717 / B J S T R .2020 .28 .004691$

Ombugadu A. Biomed J Sci \& Tech Res

(C) This work is licensed under Creative

Commons Attribution 4.0 License

Submission Link: https://biomedres.us/submit-manuscript.php

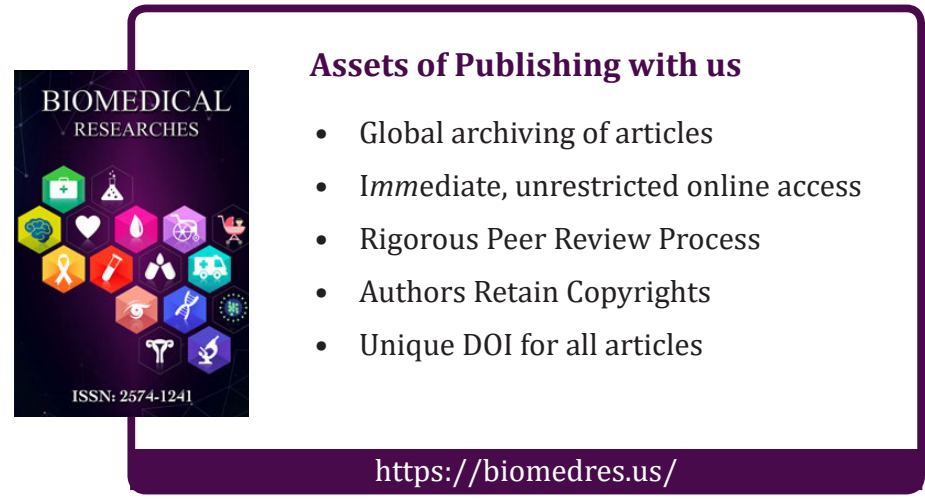

